\title{
REVISTA AONDE VAMOS? UM PROJETO JUDAICO BRASILEIRO
}

\section{MAGAZINE AONDE VAMOS? A BRAZILIAN JEWISH PROJECT}

\author{
Lucia Chermont*
}

\begin{abstract}
Resumo: O objetivo deste artigo é realizar uma análise da revista Aonde Vamos? (RJ, 1943-1977), um semanário de grande projeção na comunidade judaica nacional, nas suas redes e conexões nacionais. Esta revista tinha forte viés crítico e ideológico, veio à luz durante um período de grandes transformações, como a integração e a afirmação desse grupo frente ao trágico legado do Holocausto e às expectativas da então recente e tensa fundação do Estado de Israel. No Brasil, além das questões internacionais era o período de ascensão e integração para a comunidade judaica brasileira. $\mathrm{O}$ artigo propõe-se a responder como se davam as estratégias frente às restrições impostas pela ditadura do Estado Novo à imprensa imigrante, quem eram os mediadores dentro e fora da comunidade judaica e as redes que foram construídas e contribuíam para a projeção da revista nos seus mais de trinta anos de existência.
\end{abstract}

Palavras-chave: Imprensa judaica no Brasil. Revista Aonde Vamos?. História Contemporânea.

\begin{abstract}
The purpose of this article is to carry out an analysis of the magazine Aonde Vamos? (RJ, 1943-1977), a weekly of great projection in the national Jewish community, in its national networks and connections. This magazine had a strong critical and ideological bias, it came to light during a period of great changes, such as the integration and affirmation of this group in the face of the tragic legacy of the Holocaust and the expectations of the then recent and tense foundation of the State of Israel. In Brazil, in addition to international issues, it is the period of ascension and integration for the Brazilian Jewish community. The article proposes to answer how the strategies were given in the face of the restrictions imposed by the Estado Novo dictatorship on the immigrant press, who were the mediators inside and outside the Jewish community and the networks that were built and contributed to the projection of the magazine in its most thirty years of existence.
\end{abstract}

Keywords: Jewish Press in Brazil. Aonde Vamos? magazine. Contemporary History.

O período ditatorial denominado Estado Novo (1937-1945) impôs restrições formais às comunidades consideradas estrangeiras, que foram forçadas a se "nacionalizar", embora os parâmetros dessa nacionalização e suas exatas diretrizes não estivessem totalmente delimitados, mas não deixava escapar seu caráter ideológico xenófobo pautado num ideário que pretendia rechaçar e suprimir tudo que fosse estrangeiro. Dessa forma, pretendia promover a construção de uma nacionalidade ancorada em aspectos de uma brasilidade genuína.

Dentro dessa proposta em 1939, foi criado por decreto do presidente Getúlio Vargas o Departamento de Imprensa e Propaganda (DIP), com objetivo de promover e controlar os meios de comunicação e as atividades culturais do país (Decreto-lei 5077). Por fim, em 1941, depois de um processo gradual de restrições, um despacho do Departamento de Imprensa e Propaganda (DIP) foi emitido proibindo a edição de jornais e revistas em língua estrangeira no país.

Esse decreto, que proibia as publicações em língua estrangeiras interrompeu uma importante fase da imprensa judaica publicada em língua ídiche no Brasil e apresentou um desafio às comunidades imigrantes que foram obrigadas a adaptarem-se e expressarem-se na mídia impressa definitivamente em português.

A imprensa judaica em português já tinha dado seus primeiros passos, segundo o historiador Nachman Falbel ${ }^{1}$ com a primeira publicação, A Columna (1916-1917, RJ), fundada

\footnotetext{
* Doutoranda em História Social pela UNESP / Franca. Email: <lucichermont@ gmail.com>.

${ }^{1}$ FALBEL, 2008, p. 775.
} 
por David José Perez, advogado, jornalista, figura de prestígio na comunidade judaica filho de judeus marroquinos que se estabeleceram no Pará que não falavam ídiche, e Álvaro de Castilho engenheiro natural do Rio de Janeiro. Não judeu, ele pertencia à religião Nova Jerusalém e foi grande colaborador de Perez 2 . Outra iniciativa foi o Correio Israelita (1921-1923, RJ) do próprio Peres, com Jacob Schneider e Eduardo Horowitz. Ainda na década de 1920, surgiu a Ilustração (08/1928-06/1929, RJ), uma revista mensal de iniciativa de Adolfo Aizen. A Revista Israelita (1933-1934, RJ) também mensal, tinha direção de Abrão Koogan e o chefe da redação era Salo Brand.

A comunidade judaica paulista também se aventurou na produção de periódicos em português, como A Civilização (1932-1938, SP) como semanário empreendido por Fernando Levisky. O jornal em ídiche San Pauler Iídeche Tzeitung (Gazeta Israelita de São Paulo, 19311941, SP) começou a editar um suplemento semanal em português, chamado A Notícia (19351936, SP) que se assemelhava à Ilustração Israelita do Rio de Janeiro. Houve a revista mensal Páginas Israelitas (1937, SP) liderada por Nelson Wainer, de curtíssima duração, restringindose a alguns meses. A Crônica Israelita (1938-1969, SP), quinzenal pertencia à Congregação Israelita Paulista, fundada por refugiados do nazismo que vieram para o Brasil, apareceu em agosto de 1938 com o nome Mitteilungen der Congregação Israelita Paulista, todo em alemão. Na edição de 15/10/1938 mudou o nome para Crônica Israelita órgão oficial da Congregação Israelita Paulista, com artigos em alemão e anúncios em português. Em meados de 1939 foi publicada toda em português, em função do ato legal que impunha a tradução para o português de artigos escritos em língua estrangeira e que depois, proibiu totalmente o uso de qualquer língua que não fosse o português nos periódicos brasileiros. No entanto, a imprensa judaica publicada em português não tinha em geral vida longa, com exceção da Crônica Israelita vinculada à Congregação Israelita, que se adaptou à nova legislação do Estado Novo.

A revista Aonde Vamos? surgiu em 1941, na cidade do Rio de Janeiro, como um suplemento de turismo. No entanto, na edição de 11/03/1943 os leitores foram informados que este é o exemplar número 1 (um) e, na contracapa é apresentada uma discreta chamada "Aos leitores", a qual informa que a publicação torna-se autônoma e aquele era o primeiro exemplar de nova fase da revista. Essa nova fase publicada, em português, durou ininterruptamente de 1943 e 1977, ou seja, trinta e quatro anos e foi distribuída para todo o Brasil. Era um hebdomadário publicado às quintas-feiras e manteve essa regularidade por trinta e um anos. Somente de 1975 em diante, começou a sair de forma irregular até o final da revista. Um grande sucesso editorial da comunidade judaica carioca.

Sobre os responsáveis por essa nova fase da revista está consolidada na produção da historiógrafa sobre a imprensa judaica no Brasil a ideia que Aron Neumann e Shabetai Karakuchanski foram os fundadores da revista, no entanto, essa afirmação sobre Aron Neumann foi uma construção difundida após a sua morte. Houve uma nota na edição de 19/08/1943 sobre o novo colaborador da revista Aron Neumann cinco meses depois do surgimento da revista. Num relato autobiográfico com o título sugestivo de "Como a Aonde Vamos? chegou a ser o que é” publicado na Aonde Vamos?, em 27/09/1962, p. 46 a 63 e republicado após a sua morte em 01/02/1973, dividido, sequencialmente em vários exemplares, Neumann deixa claro que se associou à revista quando esta já existia. No entanto na primeira edição do ano 1974, ele constou como fundador da revista e, assim, permaneceu até o final, em 1977, o que pode ter fortalecido tal afirmativa. Foi realizada uma entrevista com Ronald Fucs ${ }^{3}$, o último diretor da revista de 07/03/1974 até 12/09/1977, que informou que trabalhava na revista desde 1968, primeiro como tradutor e depois como assistente de redação antes de assumir a direção. Na entrevista ao ser

\footnotetext{
2 OLIVEIRA, 2017, p. 3.

${ }^{3}$ Entrevista cedida a Lucia Chermont por Ronald Fucs, via WhatsApp, em 30/09/2020.
} 
perguntado se o Aron Neumann foi o fundador da revista respondeu categoricamente que sim, ou seja, essa era uma ideia convencionalmente aceita nos últimos anos do periódico.

No relatório confidencial da Policia Civil do Distrito Federal de 28/11/1943, denominado "Caso Aron Neumann", realizado pelo chefe do serviço secreto, que afirma que os sócios da revista são: Ladislau Vinhaes, Bela Karakuschanski e Isidoro Waisman ${ }^{4}$. Mas quem são esses personagens?

Bela Karakuschanski era esposa do jornalista Shabetai Karakuchanski, ele escrevia nos primeiros anos da nova fase da revista. Shabetai Karakuchnski veio da Argentina, onde era professor para juntar-se ao seu irmão no Rio de Janeiro e teve intensa atuação na imprensa em língua ídiche: foi redator do Dos Iídiche Vochenblat (RJ, 1923-1927); redator adjunto do Brasilianer Iídiche Presse (RJ, 1927-1929); redator de seções, articulista e financiador do Iídiche Folkszeitung (RJ, 1927-1940).

Ladislau Vinhaes Weinberg, advogado, formado na Escola Livre de Direito do Distrito Federal, em 1937, jornalista e brasileiro nato. Foi nomeado, por decreto, para o cargo de oficial administrativo do Ministério da Justiça, em $1938^{5}$, recebeu o registro de jornalista profissional, em $1939^{6}$, e foi nomeado pelo presidente Getúlio Vargas, por decreto, escrivão classe F, em $1940^{7}$. Foi encontrado um anúncio na Aonde Vamos?, em 19/01/1950, página 10:

O economista Manoel Ingber prof. de contabilidade do Instituto Comercial do Rio de Janeiro põe à disposição do Comércio e da Indústria os seus serviços de Administração - contabilidade - contratos - distrato - marcas e patentes - repartições públicas. Imposto de renda e naturalizações. Departamento jurídico sob direção do advogado Ladislau Vinhaes causas cíveis, comerciais e trabalhistas.

Ladislau teve atuação na vida política, participou da criação oficial da Aliança Social Democrata (1945-1964), como partido, em 30/05/1945, tornando-se secretário-geral do Diretório Central do partido e seu representante junto ao TSE. No entanto, no final do ano, saiu como candidato a deputado federal, pelo Partido Agrário Nacional (1945-1947) ${ }^{8}$, não sendo eleito. Como jornalista trabalhou nos jornais Correio da Noite (1935-1954, RJ), Diário Carioca (1928-1965, RJ) e o Imparcial (1935-1942, RJ). Faleceu em 17/09/1950, no Rio de Janeiro9.

Isidoro Waisman, advogado, no relatório confidencial da Policia Civil do Distrito Federal consta que Isidoro era filho de Rosa Waisman, presidente do Lar da Criança Israelita do Rio de Janeiro. Seu nome apareceu na edição da Aonde Vamos? de 03/03/1944 como representante da sucursal São Paulo até 25/05/1944.

Num período de vigência das restrições da imprensa em língua estrangeira, o governo não concedia alvará de licença nem para periódicos em português, com a intenção de impedir a publicação de novos impressos. Segundo Maria Helena Capelato ${ }^{10}$ "A partir de 1940, 420 jornais e 346 revistas não conseguiram registro no DIP”. Ao que tudo indica, a aquisição do periódico deu-se dessa forma para contornar as restrições do governo brasileiro em conceder

\footnotetext{
4 <https://www.arqshoah.com/arquivo/505-arq-495-relatorio-sobre-o-caso-aron-neumann-ainda-incompleta>.

${ }^{5}$ Jornal Carioca, 15/09/1938.

${ }^{6}$ O Jornal, 24/03/1939.

${ }^{7}$ Diário carioca, 09/04/1940.

${ }^{8}$ Partido Agrário Nacional (PAN) foi um partido político brasileiro fundado em 1945, fundado pelo fazendeiro Mário Rolim Teles. Em 1947, o PAN fundiu-se com o Partido Popular Sindicalista e o Partido Republicano Progressista, de Ademar de Barros, em 1947, para formar o novo Partido Social Progressista (1946), que foi o quarto maior partido do país entre 1947 e 1965, quando foi extinto.

${ }^{9}$ O Jornal 24/09/1950.

${ }^{10}$ (CAPELATO, 1999. p. 173)
} 
alvarás para novas publicações e pela desconfiança do governo com os jornais das comunidades imigrantes. Dessa maneira para a viabilização da imprensa judaica em português, naquele momento, era necessária uma interação, criação de estratégias e arranjos maiores do que as representadas pela imprensa em língua ídiche, com indivíduos ou grupos de fora da comunidade judaica.

No primeiro ano de existência o único nome que constava na revista era o de Ladislau Vinhaes, como diretor até 15/06/1944. O relatório confidencial da Policia Civil do Distrito Federal, de 28/11/1943, antecipava o motivo e a saída do diretor

\begin{abstract}
Aliás o diretor da revista, Ladislau Vinhaes, tem ideia de vender sua parte da revista, em virtude de suas ocupações como redator sub-Secretário do Correio da Noite e Escrivão da Polícia Civil (para o qual voltou há pouco mais de um mês) não lhe permitem o cuidado que uma publicação semanal requer. Além disso não tem grande entusiasmo pela mesma, pois é ESPIRITA.
\end{abstract}

O novo diretor, Leão Padilha, surgiu na edição de 15/06/1944 tendo permanecido no cargo por vinte e nove anos, até 14/02/1973. José Leão Padilha (29/05/1906, PI-06/06/1986, $\mathrm{RJ}$ ), formou-se em advocacia, contudo sua vida foi bastante voltada ${ }^{11}$ ao jornalismo, tendo ocupado cargos de importância em vários jornais cariocas. Foi secretário e coordenador dos jornais O Dia (1951-atual, RJ) e A Noite (1911-1957, RJ), foi jornalista e redator chefe de $A$ Notícia (1894-1930; 1938-1979; 1991-1997, RJ) e outros periódicos. Um dos fundadores da Associação Brasileira de Imprensa.

Padilha também durante vários anos, ocupou o cargo de diretor da empresa do político Antônio de Pádua Chagas Freitas ${ }^{12}$ (04/03/1914-30/09/1991, RJ) jornalista, advogado e político. Como político Freitas teve atuação nos seguintes cargos: deputado federal do Distrito Federal de 1955 a 1960; deputado federal da Guanabara de 1960 a 1971; governador da Guanabara de 1971 a 1975 e do Rio de Janeiro de 1979 a 1983.

Na imprensa Freitas foi proprietário de dois veículos de informação, comprou o jornal $A$ Notícia (1894-1930; 1938-1979; 1991-1997, RJ), em 1949, cuja linha editorial baseava-se na publicação de denúncias sensacionalistas em linguagem popular, tendo Ademar de Barros como sócio e, como secretário de redação José Leão Padilha. Manteve o estilo sensacionalista, mas utilizou o periódico como divulgação de seu partido, o Partido Social Progressista (PSP). Em junho de 1950, Chagas fundou outro jornal, O Dia (1951-atual, RJ), mais uma vez em sociedade com Ademar, aproveitando o corpo de funcionários e os contratos de publicidade do veículo que já dirigia.

Em março de 1956, Ademar de Barros exilou-se para escapar de uma pena de dois anos de reclusão, imposta pelo Tribunal de Justiça de São Paulo por desvio de verbas públicas. Chagas Freitas realizou uma estratégia de exclusão de Ademar de Barros da sociedade, tornouse assim sócio majoritário e adquiriu o controle acionário dos jornais. Além do controle direto sobre $O$ Dia e A Notícia, Chagas exercia grande influência nos meios jornalísticos cariocas e, em 1956, foi eleito presidente do Sindicato das Empresas Proprietárias de Jornais e Revistas, cargo em que permaneceu até 1970.

\footnotetext{
11 A Aonde Vamos? de 08/12/1949, página 22, tem um anuncio dos drs. Leão Padilha e Humberto A. Ribeiro advogados no Cível, Comercial, Criminal, Trabalhista e Administrativo. Homologação de sentenças estrangeiras e naturalizações.

12 <http://www.fgv.br/cpdoc/acervo/dicionarios/verbete-biografico/antonio-de-padua-chagas-freitas>.
} 
No entanto, segundo Ronald Fucs, último diretor da revista, o principal motivo da aproximação de Padilha com a comunidade judaica deve-se ao seu trabalho de advogado, auxiliando nos processos de naturalização de estrangeiros ${ }^{13}$.

Pode-se observar intensas relações da comunidade imigrante com a sociedade local favorecendo a construção e criação de uma rede baseada num cruzamento de interesses legais, comerciais e afetivos, com o advogado envolvido nos processos de naturalização dos imigrantes, seu vínculo com empresas jornalísticas, que se articulam e fortalecem mutuamente e que tinham também vínculos profundos com a política, pois eram veículos de divulgação do político carioca Chagas Freitas. Neste sentido, até mesmo a impressão da revista Aonde Vamos? foi facilitada após 1969 por utilizar as gráficas dos jornais de Chagas, como informa Ronald Fucs.

Somente em 26/06/1952, constou o nome de Aron Neumann como redator-chefe juntamente com o nome do diretor Leão Padilha. Essa foi uma parceria de sucesso que durou 21 anos e só terminou com o falecimento de Neumann, em 08/02/1973. No entanto, sabe-se que escrevia na revista desde da edição de 19/08/1943, quando sai uma nota de boas-vindas ao novo colaborador.

Aron Neumann nasceu, em 1908, em Kempen, uma cidade pequena ao Norte da Alemanha, de família ortodoxa vinculada ao movimento Aguda Israel, que combatia o sionismo e o judaísmo reformista. Neumann mudou-se para o Chile aos treze anos e com 23 anos veio para o Brasil, estabelecendo-se no Rio de Janeiro. Tornou-se sionista já adulto, militou no sionismo revisionista, a direita sionista. Fundou o Lar da Criança Israelita em 1937 instituição em atividade até os dias de hoje, trabalhou na Relief (Sociedade Beneficente Israelita de Amparo aos Imigrantes). Participou da direção do Partido dos Sionistas Gerais, em Israel, em 1961, e colaborou com inúmeras outras instituições judaicas.

Sobre como Neumann aproximou-se da revista, há duas fontes: o relatório confidencial da Policia Civil do Distrito Federal de 28/11/1943 denominado "Caso Aron Neumann", e o artigo "Como a Aonde Vamos? chegou a ser o que é" escrito por ele, publicado na Aonde Vamos? em 27/09/1962, p. 46 a 63 e republicado após a sua morte em 01/02/1973, dividido sequencialmente, em vários exemplares. No relatório confidencial Ladislau informa que foi apresentado a Aron Neumann por Shabatai Karakuchanski três meses antes, ou seja, em agosto, e sendo elemento conhecido na coletividade israelita carioca pediu para escrever uma coluna na revista para fazer críticas, mostrar os defeitos e as irregularidades nas sociedades de beneficência, maioria das quais fazia parte. A seção foi aprovada e denominada "DE PASSAGEM...", no entanto, informava que desconhece a vida pregressa de Neumann, relatando que ele causou confusão na coletividade em função de campanhas publicadas na seção e fez algumas denúncias de má conduta sobre Neumann.

No artigo modestamente intitulado "Como a Aonde Vamos? chegou a ser o que é", Neumann escreveu que sentiu forte ímpeto de se tornar jornalista e denunciar as irregularidades das lideranças comunitárias, tanto internacional, como local. Assim, em 1942, decidiu criar um periódico para dirigir-se aos judeus do Brasil, mas era impossível criar uma publicação nova, sob o regime do Estado Novo, o único recurso era adquirir um título já existente. O que confirma a hipótese que a compra de a Aonde Vamos? deu-se para driblar as imposições governamentais do período. Neumann então procurou Herbert Moses ${ }^{14}$, que o informou sobre uma revista chamada Máquina Fotográfica, que estava à venda. Outra possibilidade surgiu de "um nãojudeu de elevadas qualidades morais e arraigada formação democrática", José Leão Padilha que lhe ofereceu para comprar o título Coletânea, quando foi procurado pelo grupo que publicava

\footnotetext{
${ }^{13}$ Entrevista cedida a Lucia Chermont por Ronald Fucs, via WhatsApp, em 30/09/2020.

${ }^{14}$ Herbert Moses (1884-1972) advogado e jornalista, que fundou juntamente com Irineu Marinho o jornal $O$ Globo (1925-atual) e o jornal A Noite (1911-1957), foi presidente da Associação Brasileira de Imprensa, a ABI, (19311965) e do Instituto Cultural Brasil-Israel
} 
a Aonde Vamos?. Segundo Neumann a revista depois de três meses de publicação estava sem condições econômicas para sobreviver e necessitava de apoio para se reerguer. Ele hesitou a princípio, pois não sabia se poderia sustentar sua independência jornalística associando-se a três pessoas que mal conhecia. Vinculou-se à revista, mas logo ficou decepcionado com o nível do periódico que não atendia seus propósitos de debater os problemas comunitários. Pensou em largar a publicação e adquirir outro título para fazer uma revista judaica independente, que, segundo sua visão, o momento necessitava. Mas percebeu que já era impossível desfazer-me do encargo assumido e permaneceu até a sua morte.

Ao entrar na Aonde Vamos? Aron Neumann tinha a intenção de realizar denúncias das irregularidades das lideranças e instituições judaicas, uma proposta não muito agregadora. Dono de uma personalidade intempestiva ao longo de sua trajetória, teve mais inimigos do que amigos, e foi o provável motivo da maioria dos afastamentos da revista. Rompeu de forma radical com quase todas as instituições que atuou fazendo fortes denúncias públicas, como é o caso da Relief. O que faz ainda mais relevante sua longa permanência na revista, onde criticava e acusava publicamente todos que fossem opostos aos seus valores e opiniões. Não foi o fundador, mas teve grande protagonismo e deixou sua marca. Foi ao longo do tempo excluindo as vozes opositoras e sobressaindo-se a sua. Em função dessa tendência de não harmonizar com as lideranças da comunidade judaica local, nacional e internacional, em 24/08/1950 acrescentou ao título da revista o subtítulo, em português e hebraico, na capa "Semanário Judaico Independente do Brasil”".

Muito interessante são os comentários do jornalista Alberto Dines sobre a revista e seu redator-chefe "... era uma grande revista que eu detestava, de extrema direita, rancorosa, ás vezes desonesta, mas que acompanhou a vida judaica com espirito jornalístico" ${ }^{15}$. Neumann tinha o costume de dar voz nas páginas da revista aos seus opositores, falavam mal dele ou coisa parecida, ele publicava e comentava, os comentários eram bastante agressivos. Outro comentário do jornalista sobre o redator e a revista: "cada semana, Aron Neumann, o editor da revista, inventava alguma denúncia [...] o que a Aonde Vamos? tinha de interessante eram seus colunistas de cultura" ${ }^{16}$. A revista não se limitava às denúncias do redator-chefe e da sua visão sionista de direita, tinha artigos sobre música, literatura, teatro, cultura judaica, os intelectuais da coletividade tinham amplo espaço, além de informações e colunas fixas sobre outras cidades pelo Brasil afora.

Pelo visto não era intenção de Neumann criar uma grande rede de contatos pelas cidades do Brasil, mas, em função da longevidade a revista acabou criando uma ampla conexão com as comunidades judaicas em várias cidades, com representantes e assinantes. Também ajudou a construir uma identidade judaico brasileira, o movimento sionista de diversas matizes, no Brasil, e criou o debate em torno dessas questões, nem sempre harmônicas.

Constam, na revista, os nomes dos representantes das sucursais das primeiras edições de publicação até 18/06/1953, a partir dessa data, aparecem somente a equipe do Rio de Janeiro, a sede, o endereço da sucursal São Paulo e, de forma genérica, agentes por todo Brasil. Verificase a penetração da revista pelo Brasil comprovada pela longa lista de sucursais e representantes que possuía. Alguns lugares conseguiram uma estabilidade nessa representação, em outros, houve uma grande variação de representantes, em geral ativistas da comunidade judaica local e alguns membros proeminente delas.

Em São Paulo, um mês depois do começo da revista surgiu o primeiro representante, em 22/04/1943, denominado correspondente Moisés Schwartzman ${ }^{17}$. No mês seguinte,

${ }^{15}$ JORNALISMO..., 2009, p. 9.

16 LEAL et al., 2013, p. 9.

${ }^{17}$ Moisés Schwartzman, faleceu em 29/03/1968, quadra 49, setor D, sepultura 45, Cemitério Israelita do Butantâ, SP. (Levantamento realizado por Paulo Valadares e Guilherme Fainguenboim nos Cemitérios Israelitas da Vila Mariana e do Butantã, SP, cedido à pesquisadora). 
20/05/1943, o representante mudou para diretor Fernando Levisky (1910-1982) que foi escritor, jornalista, advogado e autor da Enciclopédia Judaica Resumida e de outras obras. Mantinha uma "Coluna Israelita" no Diário de S. Paulo no ano de 1941. Na década de 50, promoveu uma campanha, conhecida como A campanha dos dicionários, com a finalidade de banir dos dicionários de língua portuguesa as referências ofensivas aos israelitas.

No entanto, a estabilidade do representante da capital paulista demoraria, no começo do ano seguinte não saiu publicado o representante e, na edição de 03/03/1944, apareceu, na sucursal de São Paulo, o nome de Isidoro Waisman. Seu nome consta no relatório confidencial da Policia Civil do Distrito Federal de 28/11/1943, denominado "Caso Aron Neumann", como um dos proprietários da revista. No entanto, como não foi encontrado nenhum outro documento, não foi possível verificar se, naquela data, ainda era proprietário da revista. Em 25/05/1944, só constava o endereço da sucursal sem o representante. No começo de 1945, a partir de 25/01, apareceu o novo representante: Jacob Gordon. Seu nome foi encontrado na Ata de 24/09/1933, no Fundo Ezra, sociedade de assistência mútua da comunidade judaica, no Centro de Memória do Museu Judaico de São Paulo, como sócio da instituição. Seu nome também foi encontrado no jornal Crônica Israelita de 14/12/1944, como Secretário da Congregação Israelita Paulista.

Em 31/05/1945, mais uma vez o representante mudou, Isac Wasserman ${ }^{18}$. Quase dois anos depois, a sucursal de São Paulo ganhou um sub-agente, o Sr. M. Sonntag ${ }^{19}$, que atuou no período de 04/09/1947 até 27/05/1948. Permanecendo, depois disso somente Isac Wasserman.

Na edição de 06/01/1949, só o endereço da sucursal de São Paulo aparece, sem o representante, e a partir de 26/06/1949, o nome de todos os representantes e seus endereços começaram a não aparecer na revista de maneira regular e só voltam de forma definitiva em 05/01/1950. Na edição de 24/11/1949, começou a surgir indícios do que houve, justificando essa descontinuidade, pois é publicada uma chamada, que, em função da mudança do quadro de funcionários, a sucursal São Paulo teria horário reduzido de funcionamento, das $15 \mathrm{~h}$ às $18 \mathrm{~h}$, e não consta o seu endereço. Já em 22/12/1949 publicou-se, em uma nota, que a comunidade de São Paulo, conforme o esperado pela revista, estaria respondendo plenamente ao apelo em defesa da imprensa judaica independente, seguindo-se a afirmação, que, na semana, foram registradas mais sete renovações de assinaturas, somadas às 16 da semana anterior perfazendo o total de 23 e mais 11 novas assinaturas. Na página 14, encontramos esse texto:

Pouco a pouco, com a ajuda dessas pessoas que sinceramente sentem necessidade da fiscalização da vida sionista, por intermédio de uma imprensa livre, sem outros compromissos além da defesa do interesse público, "Aonde Vamos?" recupera o terreno perdido por força das maquinações e da sabotagem com que tentaram colocá-lo à margem do "Ichuv"20 paulista.

O fato é que esse desentendimento, que, pelo que podemos compreender deu-se por divergências da linha sionista defendida pela revista, abalou seu prestígio e representação da em São Paulo. O ano de 1950 inteiro foi perpassado pela irregularidade das informações das sucursais e da nota sobre o horário reduzido da sucursal de São Paulo em função da troca de

\footnotetext{
18 Isac Wasserman faleceu 21/01/1969, Quadra 49, setor D, sepultura 131 (Levantamento realizado por Paulo Valadares e Guilherme Fainguenboim nos Cemitérios Israelitas da Vila Mariana e do Butantã, SP, cedido à pesquisadora).

19 Magnus. Sonntag faleceu 01/09/1954, Quadra 5, setor H, sepultura 50, Cemitério Israelita do Butantã, SP (Levantamento realizado por Paulo Valadares e Guilherme Fainguenboim nos Cemitérios Israelitas da Vila Mariana e do Butantã, SP, cedido à pesquisadora).

${ }^{20}$ Ishuv (em hebraico significa assentamento) é um termo hebraico que se refere aos assentamentos judeus existentes na Terra Santa antes da criação do Estado de Israel, no entanto o termo é também usado genericamente para designar a comunidade judaica de uma região.
} 
funcionários. Na edição de 30/03, ainda nessa proposta de defesa da revista, saiu publicada a comemoração do $20^{\circ}$ assinante da revista, morador de Israel, sendo que essa informação vinha acompanhada de outra, da que a revista possuía assinantes nas Américas e na Europa, mas sem a divulgação dos números. Em 27/04, uma nota apresentava que haviam contratados um agente para São Paulo capital e outro para o interior, dessa forma, temos a informação sobre a existência de assinantes e anunciante no interior do estado.

Em 1951, parece que a revista retomou seu prestígio junto aos leitores de São Paulo, mas, mais uma vez, com mudanças constantes dos representantes. Em, 05/04, a revista teve dois endereços, sem o nome dos representantes: "para Sociais, Publicidade e Assinaturas Rua Xavier de Toledo, 316 e Agência no B. Retiro: Livraria Weltman”. A Livraria Weltman permaneceu até 26/06, quando foi substituída por "INTERIOR DE SÃO PAULO Revistas Especializadas do Brasil (representação exclusiva) ", que também teve curta duração — até 20/11. Em 28/06, surgiu a sucursal de Santos, com o representante Jacob Chivindelman, mas só durou até 22/11 do mesmo ano. O que permaneceu foi o endereço da rua Xavier de Toledo.

No ano de 1953 houve uma mudança na diagramação e local de publicação das informações gerais da revista, sendo que, em18/06, apareceu somente: "sucursal São Paulo, Rua Xavier de Toledo,316 e agentes por todo Brasil”.

A sucursal Curitiba apareceu em 1945, no exemplar de 25/01/1945, representada pelo Boruch Bariach, que foi um importante nome do sionismo brasileiro, de origem polonesa, que desembarcou no Brasil em 1931. Em 1933, assumiu a direção da Escola Israelita Brasileira de Curitiba, permanecendo em sua direção por mais de uma década. A pedido da Organização Sionista do Rio Grande do Sul, em 1947, mudou-se para Porto Alegre, a fim de dirigir o Instituto de Educação e Cultura (Colégio Israelita, criado em 1922), ensinar a língua hebraica à juventude e desenvolver atividades de caráter sionista na comunidade local ${ }^{21}$.

Somente em 1947, houve a mudança de representante de Curitiba na revista, muito provavelmente em função da transferência de Bariach para Porto Alegre. Em 30/01, o novo representante era Marcos Raisman, que ficou até 27/05/1948. A revista permaneceu sem representante em Curitiba até 24/06/1948, quando surgiu Isaac Schilklapper, médico, que na faculdade na Universidade Federal do Paraná, foi o fundador, com outros colegas, do primeiro curso preparatório para vestibular de Medicina, Odontologia e Farmácia, o curso Oswaldo Cruz (1949-1965). Portanto, foi representante da revista no período universitário e ficou como representante até 12/07/1951. Só ressurgiu uma representação em 15/01/1953 com Flora Gilda Orenbuch $^{22}$, que desaparece com as outras sucursais nas páginas da revista, substituídas por "agentes em todo Brasil", em 18/06/1953.

A cidade de Porto Alegre ganhou uma sucursal na mesma edição de Curitiba, 25/01/1945, com Isidoro Frantzuski, que era correspondente da revista Aonde Vamos? desde 1943. Em 04/09/1947 mudou o representante para Marcos Nestroviski (1930-2012), médico com um dos registros mais antigos no Conselho Regional de Medicina do Rio Grande do Sul. Assinava uma coluna quinzenal, denominada "Quinzena Porto-Alegrense". Em 18/05/1950, o representante mudou novamente para Samuel R. Wainer ${ }^{23}$, que permaneceu até 23/04/1953.

Belo Horizonte também consta entre as sucursais da edição de 25/01/1945, com o representante Jacob Grinberg, que participou da reorganização do sionismo em Minas Gerais, em 1945, com a formação, em Belo Horizonte, da comissão composta pelos seguintes dirigentes: Alberto Avritzer, presidente; Moisés Kraiser, vice-presidente; Jaime Kendler, $1^{\circ}$ secretário; Jacob Grinberg, $2^{\circ}$ secretário, Salomão Sternik, $1^{\circ}$ tesoureiro, Samuel Kalichman, $2^{\circ}$ tesoureiro, Isaac Cohen, prof. Abraam Chassim e José Margalith, Comissão cultural e

\footnotetext{
${ }^{21}$ BARTEL, 2015, p. 142.

${ }^{22}$ Flora Gilda Orenbuch (1934, RJ - 2015, PR).

${ }^{23}$ Não se trata do Samuel Wainer criador do jornal Última Hora, mas de um homônimo.
} 
propaganda ${ }^{24}$. Na revista Aonde Vamos? encontramos anúncio do advogado Jacob Isac Grinberg em Belo Horizonte. Nessa sucursal não houve troca de representante, mas da edição de 30/04/1953 em diante, não sai mais publicada a sucursal Belo Horizonte.

Em 06/04/1945 surgiram outras sucursais, como a da Bahia, representada por Abraão Zaverucha $^{25}$. No ano seguinte, na edição de 29/08/1946, mudou o representante para Saul Zaverucha $^{26}$. Em 10/07/1952 mudou o representante para Jaime Zaverucha ${ }^{27}$ até a edição de 18/06/1953, quando deixam de ser publicadas as sucursais na revista. Os representantes da sucursal da Bahia são irmãos que foram se alternando na representação da revista em Salvador.

Outra sucursal que teve origem na edição de 06/04/1945 foi a de Recife, com o representante Elias Roitman. No entanto, logo o representante mudou para David Fassberg, em 22/11/1945. Informações sobre a família de David Fassberg foram encontradas na dissertação de mestrado de Luciana Souza de Oliveira ${ }^{28}$ sobre a comunidade judaica de Natal: Moisés Fassberg veio casado para Natal, tendo chegado em 1928. Tinha dois filhos, Netti Fassberg, que foi a primeira estudante judia natalense a frequentar a Universidade no Recife, fato prontamente anotado no livro da comunidade de Natal no dia 11/07/1930; e David Fassberg, que estudava no Jardim de Infância Israelita. Moisés Fassberg chegou a ser presidente do Centro Israelita de Natal no ano de 1931. David Fassberg permaneceu na representação da revista quase dois anos e, em 06/02/1947, o representante mudou para Manoel Averbuch ${ }^{29}$, sendo que, somente em 04/01/1952, mudou para Mauricio Averbuch ${ }^{30}$, que continuou até 18/06/1953 quando deixam de constar as sucursais na revista.

No ano de 1946, apareceu a sucursal de Belém representada por Samuel Benchimol, o que consta na edição de 05/12/1946, e que se tem registro até 08/05/1947. Samuel Isaac Benchimol (13/07/1923-07/05/2002, Manaus) foi um destacado membro e ativista da comunidade judaica de ascendência marroquina de Manaus, foi presidente do Comitê Israelita do Amazonas, professor Emérito da Universidade do Amazonas, catedrático da disciplina "Introdução à Amazônia" e co-fundador do grupo Bemol-Fogás, em 1942. Estudou à região amazônica, seus aspectos sociais na economia e no desenvolvimento sustentável no entorno do rio Amazonas, publicou 109 trabalhos e foi membro da Academia Amazonense de Letras. Dedicou-se também, de forma pioneira, ao estudo dos judeus marroquinos no Norte do país, no período do Ciclo da Borracha. Em 2006, foi criado o Prêmio (anual) Professor Samuel Benchimol e Banco da Amazônia de Empreendedorismo Consciente para apoiar pesquisas que contribuam para o entendimento e sustentabilidade da região amazônica.

Depois da saída de Benchimol a revista ficou sem sucursal em Belém até 30/10/1947, quando Isaac Ramiro Bentes ${ }^{31}$ assumiu o cargo, ficando até 27/05/1948. Mais uma vez, a revista ficou sem a sucursal até ressurgir em 16/12/1948 com Maluf Gabbay ${ }^{32}$. Em 16/06/1949 mudou novamente o representante para José Lancry e, em 19/03/1953 foi descontinuada a publicação

\footnotetext{
${ }^{24}$ BARTEL, 2015, 151.

${ }^{25}$ Abraão Zaverucha (01/10/1922, BA- 28/01/2003, PE).

${ }^{26}$ Saul Zaverucha (1925, BA - 2013, PE), engenheiro civil e professor do Departamento de Engenharia Civil da UFPE por trinta anos. Era irmão do representante anterior da Bahia, Abraão Zaverucha, informação cedida por David Paves.

${ }^{27}$ Jaime Zarevucha foi engenheiro, irmão de Abraão e Saul Zaverucha, tornou-se nome de rua em Salvador.

${ }^{28}$ (OLIVEIRA, 2009, p. 90)

${ }^{29}$ Nada foi encontrado sobre Manoel Averbuch, mas o pai de Mauricio Averbuch chamava Marcos Averbuch, não sabemos se adotou o nome Manoel ou trata-se de outra pessoa com o mesmo sobrenome.

${ }^{30}$ Mauricio Averbuch (1924 - 1991, PE).

${ }^{31}$ Isaac Ramiro Bentes (? - 1956, PA) descendente de judeus marroquinos que se estabeleceram no Norte do Brasil e irmão do Abraham Ramiro Bentes, oficial do exército brasileiro e autor de Os Sefardim e a Hakitia (1981); Das Ruinas de Jerusalém a Verdejante Amazônia: Formação da 1a. Comunidade Israelita Brasileira (1987); Primeira comunidade israelita brasileira: tradições, genealogia, pré-história (1989).

${ }^{32}$ Maluf Gabbay (20/05/1924, Breves, PA - 11/03/1985, Belém, PA).
} 
da sucursal Belém. Sobre o representante dessa sucursal, no período em que não constam mais os nomes dos representantes, tem-se por relato de Yehuda Benguigui e do antropólogo Wagner Lins, que, nas décadas de 1960 e 1970, o representante foi Manoel Kislanov de origem russa, um dos pouquíssimos asquenazim (judeus de origem europeia) da comunidade judaica de Belém.

A última sucursal a surgir foi a sucursal de Manaus, em 04/09/1947, com representação de Fortunato Siqueira (? - 1993, Manaus). Seu nome aparece na Folha Israelita - órgão da Coletividade Israelita Brasileira no Amazonas de 01/1949, como comerciante e representante da revista Aonde Vamos? e como correspondente do Amazonas na revista da Associação Comercial - publicação mensal da Confederação das Associações do Brasil, da Federação das Associações Comerciais, Industriais e Agropastoris do Estado do Rio de Janeiro e da Associação Comercial do Rio de Janeiro, 08 e 09/1989. Permaneceu como representante até o fim da publicação das sucursais na edição de 18/06/1953.

Verifica-se pela exposição dos representantes da revista que ela mobilizou membros da comunidade judaica de oito capitais e, provavelmente outras cidades de norte a sul, São Paulo, Curitiba, Porto Alegre, Belo Horizonte, Salvador, Recife, Belém e Manaus, a investirem seu tempo procurando assinantes, vendendo anúncios, mandando informações para preencher as colunas dedicadas aos acontecimentos locais, sejam de casamentos, bar mitzvot, nascimento, falecimento, eventos culturais e comemorações comunitárias. Ou seja, uma ampla rede nacional em torno da vida comunitária, dos debates nacionais e internacionais que mobilizavam seus membros.

Depois do falecimento de Neumann, em 08/02/1973, José Padilha ficou na revista até 14/02/1973, quando apareceu pela última vez o seu nome como diretor da revista. Na edição de 07/03/1974, juntamente com "Fundador Aron Neumann", que surge desde o começo do ano, foi apresentada a nova equipe da revista: Diretor Ronald Fucs (20/03/1942, BA) matemático pela UFRJ, porém teve a vida dedicada ao jornalismo e a dramaturgia. Foi professor, roteirista da TV Globo, jornalista de economia e editorialista do jornal O Globo e, desde 2002, proprietário da editora Caravansarai. Escreveu os livros Luta nas Classes e Enlouquecendo em Família em parceria com Bernardo Jablonski ${ }^{33}$, e $O$ passarinho que não sabia cantar de literatura infantil. No teatro, participou de peças como ator, autor e compositor da trilha.

Sobre como começou a trabalhar na revista, Fucs conta que começou a fazer traduções para empresas e editoras, foi contratado para traduzir o livro Arte Judaica de Cecil Roth, publicado em 1967. Depois desse trabalho, aproximou-se da revista, em 1968, a princípio traduzindo textos, depois, a convite de Aron Neumann, como assistente de redação. Ressalta que, apesar de seu pai ser judeu, não teve educação judaica, foi criado como cristão e desconhecia completamente a dinâmica comunitária, as questões ideológicas sionistas e subgrupo judaico ao qual a revista pertencia. Quando Aron Neumann faleceu, foi descoberto um número exorbitante de dívidas em nome da revista, que recaíam sobre Leão Padilha proprietário da Aonde Vamos?. Depois de muitas negociações com o contador, pagaram uma parte da dívida. Padilha tirou seu nome da revista e, para não ser responsável pelas dívidas, ela não poderia fechar até dois anos depois da saída dele. Foi neste contexto que Fucs responsabilizou-se pela direção da Aonde Vamos? ${ }^{34}$

Ao lado de Fucs, temos o nome de Esther Ita Feldman (23/11/1909, Varsóvia07/03/1999, Ra'anana, Israel) como redatora-chefe da Aonde Vamos?. Ela enviou uma carta ao Jornal do Brasil, em 15/01/1976, que saiu publicada nas cartas do leitor na página 2, criticando a matéria "A numerosa imprensa dirigida que muitos desconhecem" publicada na última página

\footnotetext{
${ }^{33}$ Bernardo Jablonski (01/01/1952-28/10/2011, RJ) foi um ator, diretor teatral, escritor, crítico e roteirista. Doutor em Psicologia Social, professor universitário e autor de vários livros. Na TV, seu trabalho mais popular foi o papel de "Aderbal", no extinto Zorra Total da Rede Globo, do qual era também roteirista.

${ }^{34}$ Entrevista cedida a Lucia Chermont por Ronald Fucs, via WhatsApp, em 30/09/2020.
} 
do Caderno B do dia 10 daquele mês e fez os seguintes esclarecimentos: que trabalhava na revista Aonde Vamos? desde 1960, e, na condensação de suas palavras, na matéria foi omitido o papel preponderante que imprimiu à revista o seu fundador, Aron Neumann. Após seu falecimento, ela substituiu-o por três anos. Dessa forma, tomamos conhecimento de que seu envolvimento na revista é anterior ao seu cargo de redatora-chefe e, mais uma vez, a ideia consolidada, de maneira equivocada, de Neumann ser o fundador da revista.

Antes do final do ano, em 30/11/1975, apareceu mais um redator: Redatores Esther Feldman e Isaac Akcelrud. A presença desse redator na revista mostra claramente que ela estava em outro momento, Isaac Akcelrud (1914, RS-1994, RJ) filiou-se ao PCB em 1936 na juventude comunista gaúcha. Sua militância durante os vinte anos seguintes concentrou-se na imprensa popular do PCB, tendo sido editor de vários de seus jornais, inclusive diários no Rio de Janeiro e em São Paulo. Foi um dos líderes da dissidência do PCB após a divulgação do Relatório Kruschev, em 1956, e passou a apoiar correntes antistalinistas. Posteriormente filouse ao PT na década de 1980, pertenceu ao coletivo da tendência Democracia Socialista. Militou como jornalista e organizador no movimento dos Sem-Terra. Publicou milhares de artigos dedicados ao jornalismo de esquerda, além de um livro sobre o Oriente Médio, e outro sobre a reforma agrária no Brasil. Pertencia ao movimento Paz Agora.

$\mathrm{Na}$ entrevista realizada com Ronald Fucs perguntou-se sobre a relação de Akdelrud com a revista, pois tinha um perfil bastante distinto da publicação do ponto de vista político, ao que ele respondeu que foi o redator que procurou a revista e candidatou-se para o cargo, pois ficou sabendo que estava numa situação difícil e queria ajudar. Considerava a revista de um bom nível e de importância dentro e fora da comunidade judaica. Após a morte de Neumann, ficou evidente a qualidade da equipe profissional da revista, que realizava traduções de artigos publicados em importantes veículos internacionais e matérias de um bom nível cultural e de interesse para comunidade judaica, o que possibilitou a admiração de indivíduos de outras correntes ideológicas que manifestaram sua admiração por ela.

No entanto, em 15/03/1976, o nome de Esther Feldman não consta entre os redatores, ficando somente o Diretor Ronald Fucs e Redator-chefe Isaac Akcelrud, sempre com o nome de Aron Neumann como fundador da revista. No último exemplar encontrado, tanto no Centro de Memória do Museu Judaico de São Paulo como na Biblioteca Nacional, de 12/09/1977, só constam os nomes: Fundador Aron Neumann e Diretor Ronald Fucs.

\section{Considerações finais}

A revista Aonde Vamos? percorreu longo trajeto juntamente com a comunidade judaica carioca e brasileira, primeiro, sendo obrigada a adaptar-se e criar estratégias para dar continuidade à vida comunitária nas suas várias formas no contexto pouco favorável do Estado Novo. Em contrapartida, essas ações colaboraram para uma maior integração da comunidade israelita, que tinha ainda um contorno bastante imigrante, com a sociedade brasileira. Passada essa fase, nos anos que se seguiram, principalmente no pós Segunda Guerra Mundial, que foram anos de prosperidade como um todo, a comunidade estabelecida no Brasil pode beneficiar-se daquele momento e seus veículos de comunicação também. As redes que se formaram, em torno da revista, em diversas cidades, com assinantes, representantes e anunciantes possibilitaram uma grande circulação dos impressos, de ideias e informações.

Foi possível, também, verificar as intensas relações construídas dessa imprensa comunitária com a imprensa nacional. Uma vez que o diretor da revista por vinte nove anos, 
Leão Padilha, foi concomitantemente diretor da Aonde Vamos? e dos jornais A Noite e O Dia, estes últimos propriedade do político carioca Antônio de Pádua Chagas Freitas.

Privilegiou-se, neste artigo, a perspectiva histórica baseada na circulação dos impressos e, nesse caso específico, predominantemente no Brasil, assim como a rede de mediadores, ou seja, os intelectuais e pessoas proeminentes ou não das comunidades locais que atuaram como diretores, redatores-chefes e representantes da revista. Sempre que possível buscou-se levantar o local e o perfil desse mediador entre a revista e as comunidades judaicas locais. Não foi objeto nem intenção deste artigo analisar o conteúdo da revista, mas salientar os grupos de indivíduos que se formaram, sua penetração pelo território nacional, até internacional, e as atividades desses congregantes. Interessante notar que essa circulação dos impressos e das informações nem sempre deu-se do centro para a periferia. Como no caso da revista publicada em português e no Brasil, que tinha assinantes na Europa, Américas e em Israel, assim o movimento inverso também pode ser constatado, da periferia para os centros mundiais.

Pode-se verificar, no arrolamento realizado, a existência de intelectuais reconhecidos entre os mediadores da Aonde Vamos?, como Fernando Levisky, que, nos anos 1950, promoveu importante campanha nacional para a retirada de termos antissemitas dos dicionários de língua portuguesa. Ou Samuel Benchimol membro e ativista da comunidade judaica de Manaus, também professor Emérito da Universidade do Amazonas, catedrático da disciplina "Introdução à Amazônia", em 2006, o Banco da Amazônia de Empreendedorismo Consciente criou um prêmio destinado a apoiar pesquisas que contribuam para o entendimento e sustentabilidade da região amazônica denominado: Prêmio (anual) Professor Samuel Benchimol. Ou ativista comunitário, como Jacob Gordon, que fez parte da diretoria das instituições judaicas Sociedade Beneficente Israelita Ezra e da Congregação Israelita Paulista. Demonstra-se um intenso intercâmbio entre sociedade brasileira intelectual acadêmica e a revista, ou mesmo no interior das instituições judaicas com representantes e ativistas cumprindo funções de maneira simultâneas na revista e na coletividade.

Uma das temáticas que congregou intelectuais e ativistas em torno da revista foi o sionismo. Pode-se verificar a presença como mediador da revista do proeminente emissário sionista, Boruch Boriach, que foi contratado para atuar em Curitiba e, posteriormente, em Porto Alegre. Além dele, pode-se citar Jacob Grinberg, que reuniu outros ativistas e propiciou a reorganização do movimento sionista em Minas Gerais. O quanto a revista fortaleceu esse ativismo e quanto desse ativismo favoreceu o número de assinantes e a divulgação da revista? O caso é que esses indivíduos optaram por serem representantes dessa revista e não de outra publicada pela comunidade judaica. Esse fato não é desprovido de significado, porque muito provavelmente somavam esforços e complementavam-se numa determinada direção de projeto e posturas ideológicas.

A recepção da revista, por sua vez, não foi passiva, houve conflitos, rupturas e consensos. Precisa-se destacar, ainda, que a intenção da revista e a recepção do leitor podem não ser apreendidas da mesma forma. No entanto, são justamente essas interações entre revista, mediadores, comunidade judaica brasileira, lutas e disputas pelo direito de definir o que é relevante e que possibilita salientar a ambiguidade dessa imprensa ao mesmo tempo nacional e estrangeira, no caso específico judaico brasileira, enfatizando as conexões e redes que propiciam a existência desse espaço cultural judaico vivo e dinâmico, que confere à análise do periódico um lugar original e singular.

Muito importante ressaltar que, apesar do conteúdo não ter sido objeto de análise do artigo, a imprensa em geral, para além de informar, constrói significados, hierarquiza, coloca pautas em questão. Ao priorizar por um tema ou enfoque deixando outros em segundo plano, está informando aos seus leitores o que tem importância e o que não. Está-se enfatizando a não neutralidade da imprensa enquanto veículo de informação. Neste sentido, a revista Aonde Vamos? formou e orientou seus leitores, estimulou seus redatores-chefes, diretores e 
mediadores por mais de trinta anos. Dessa forma, circulou por praticamente todas as cidades onde existia comunidade judaica organizada, no Brasil, e também fora do país, participou ativamente da construção e das reflexões sobre uma comunidade judaica brasileira.

\section{Referências}

BARTEL, Carlos B. O movimento sionista e a comunidade judaica brasileira (1901-1956). Curitiba: Editora Prisma, 2008;

CAPELATO, Maria H. Propaganda política e controle dos meios de comunicação. In: PANDOLFI, D. (Org.). Repensando o Estado Novo. Rio de Janeiro: Fundação Getúlio Vargas, 1999, p. 167-178;

JORNALISMO judeu no Brasil. Boletim ASA Associação Scholem Aleichem, Rio de Janeiro. n 120 - setembro/outubro, 2009.

FALBEL, Nachman. Judeus no Brasil - estudos e notas. São Paulo: Humanitas/ Edusp, 2008

LEAL, Bruno, GRIN, Monica, Caraciki, Leonel, NOVA, Andréa C. e KOIFMAN, Fabio. Conversando com Alberto Dines. Revista Digital do NIEJ, Rio de Janeiro, ano 4, nº 6, pg. 3 12, 2013.2 Disponível em: [https://niej.files.wordpress.com/2018/12/REVISTADONIEJNumero628-1.pdf]. Acesso em: $03 / 11 / 2020$

NEUMANN, R. M. Correio Serrano: órgão dos interesses regionais. In: DREHER, M.; RAMBO, A. B.; TRAMONTINI, M. J. Imigração e Imprensa. Porto Alegre: EST/São Leopoldo: Instituto Histórico de São Leopoldo, 2004, pp. 190-209;

OLIVEIRA, Luciana Souza de. A fala dos passos: imigração e construção de espaços judaicos na cidade de Natal (1919-1968). 2009, p. 196, (Dissertação de Mestrado em História) Universidade Federal do Rio Grande do Norte, Natal;

OLIVEIRA, Luciana Souza de. Sionismo como projeto indentitário - Rio de Janeiro (19011918). XXIX Simpósio nacional de História - contra os preconceitos: história e democracia. Brasília, $2017 . \quad$ Disponível em: [https://www.snh2017.anpuh.org/resources/anais/54/1502714762_ARQUIVO_Textocomplet oanpuh.pdf]. Acesso em: 11/11/2020. 